\title{
Narrative review of the history of microsurgery in urological practice
}

\author{
Mang L. Chen ${ }^{1}$, Gregory M. Buncke ${ }^{2}$, Paul J. Turek ${ }^{3}$ \\ ${ }^{1}$ G.U. Recon, San Francisco, CA, USA; ${ }^{2}$ The Buncke Clinic, San Francisco, CA, USA; ${ }^{3}$ The Turek Clinic, Beverly Hills, CA, USA \\ Contributions: (I) Conception and design: All authors; (II) Administrative support: GM Buncke, PJ Turek; (III) Provision of study materials or patients: \\ All authors; (IV) Collection and assembly of data: ML Chen, PJ Turek; (V) Data analysis and interpretation: All authors; (VI) Manuscript writing: All \\ authors; (VII) Final approval of manuscript: All authors. \\ Correspondence to: Mang Chen, MD. G.U. Recon, 45 Castro St, Suite 111, San Francisco, CA 94114, USA. Email: mangchenmd@gmail.com.
}

\begin{abstract}
The clinical need for magnified visualization during surgery spurred the evolution of microscope and microsuture technology. Innovative surgeons across various surgical specialties recognized the importance of utilizing and advancing these technologies. Operative microscopy allows human dexterity to perform beyond direct visual limitations. Microsurgery started in otolaryngology and ophthalmology, became popular in reconstruction and transplantation, and was then adopted in urology. Microsurgery in urology involves renal and penile revascularization, penile transplantation and free flap phalloplasty, testicular autotransplantation, reproductive tract reconstruction of the vas deferens and epididymis, varicocele repair, and sperm retrieval. By examining the peer reviewed and lay literature, this review discusses the history of microsurgery and its subsequent development as a subspecialty in urology.
\end{abstract}

Keywords: Urology; microsurgery; phalloplasty; vasovasostomy; transplantation

Submitted Nov 19, 2020. Accepted for publication Feb 25, 2021.

doi: $10.21037 /$ tau-20-1441

View this article at: http://dx.doi.org/10.21037/tau-20-1441

\section{Introduction}

Microsurgery has been instrumental to surgical advances in many medical fields. Otolaryngology, ophthalmology, gynecology, hand and plastic surgery have all embraced the operating microscope to minimize surgical trauma and scar and to increase patency rates of vessels, nerves and tubes. Urologic adoption of microsurgery began with vasectomy reversals, testis transplants, varicocelectomies and sperm retrieval and has now progressed to free flap phalloplasty and penile transplantation. In this review, we describe the origins of microsurgery, highlight the careers of prominent microsurgeons, and discuss current use applications in urology.

We present the following article in accordance with the Narrative Review reporting checklist (available at http:// dx.doi.org/10.21037/tau-20-1441).

\section{Birth of microsurgery}

\section{Technology}

The birth of microsurgery followed from an interesting marriage of technology and clinical need. The operating microscope was first introduced in otolaryngology surgery. To better enable fenestration procedures for otosclerosis of the middle ear, a surgical intern at the University of Sweden, Carl Olof Nylen [1892-1978], first introduced the microscope into the operating room in 1921 (1-3). By modifying a monocular dissecting microscope for the operative setting, his innovation inspired the otolaryngology department chair Gunnar Holmgren [1875-1954] to develop a tripod mount and add an external light source.

Borrowing a binocular operating microscope from another otolaryngologist, Richard Perritt expanded its application to the field of ophthalmology in 1946 at Loyola 


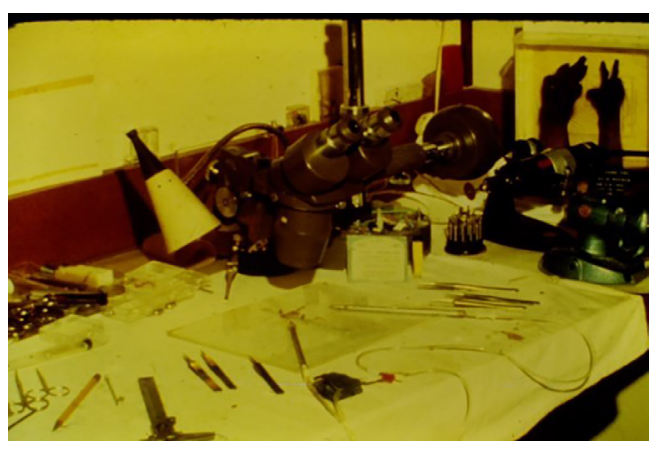

Figure 1 Photograph of Dr. Buncke's garage laboratory (Photo courtesy of Dr. Gregory Buncke).

University in Chicago $(3,4)$. His efforts changed the direction of cataract surgery.

The Zeiss Company then began to build dual Galileo telescopes capable of image scaling that, interestingly, were aimed at gynecologic surgery (3). In 1967, Kurt Swolin pioneered the microsurgical correction of fallopian tube adhesions and obstruction (5). In 1972, CelsoRamon Garcia presented the first report of fallopian tube reanastomosis, establishing the role of microsurgery in this subspecialty (6). These incremental advances in microsurgery led to its broader application across other surgical disciplines.

The first use of microsurgery in urology was used to treat vasal and epididymal obstruction. Reproductive tract reconstructive surgery had been attempted since 1902 but was associated with dismal success rates (7). In 1977, the first microsurgical vasovasostomies were reported by Drs. Owen and Silber $(8,9)$. Soon thereafter, Silber and Kelley also reported the first successful case of testicular autotransplantation of an intra-abdominal testis to the scrotum $(10,11)$. With its beginnings in reproductive medicine, microsurgery has now been integrated into many subspecialties in urology, including vascular surgery, tissue grafting, replants and robotics $(3,7,8,12-18)$.

\section{Microsuture}

Suture technology evolved by necessity with microscopy given the need for suture that was fine enough to allow anastomosis of microscopic vessels. New requirements for sutures were reduced size, increased uniformity and tensile strength, and enhanced tissue compatibility to reduce scarring. Naturally available suture materials included gold, silver, iron, steel, hair, silk, tree bark and plant fibers. The use of human hair as suture was recorded first in 1880 in the eye conjunctiva, labial mucous membranes and face (19). Due to its small diameter and good tissue compatibility, hair also had the benefit of minimizing scarring after removal. At the turn of the century, human hair was used in anastomosis of canine blood vessels. Hair was preferred over the alternative silk suture because of its greater tensile strength.

\section{The microsurgeon}

In 1894, the idea of performing vascular anastomoses was born in France, pushing the surgical skill set into the realm of microsurgery. On June 4, Marie Francois Sadi Carnot, the president of France, was stabbed in the abdomen by anarchist Sante Caseirio. The stabbing severed Carnot's portal vein, and, because surgeons lacked the ability to anastomose blood vessels, Carnot died within hours. His death deeply impacted Alex Carrel, at that time a medical student at the University of Lyon, who as a result of the event later developed the conviction that no patient under his care should ever die because of such technical shortcomings. With the aid of a seamstress, Madame Leroidier, Carrel applied the fine needling technique of embroidery to the anastomosis of blood vessels. His success in vascular anastomosis was attributed to his idea of placing 3 sutures equidistant from each other, thus forcing blood vessels to assume a triangular shape. Awarded the Nobel prize in Medicine in 1912, Carrel delivered a speech claiming that his innovation in anastomosis opened the possibility of organ transplantation and replantation of severed limbs.

It wasn't until the 1960s that the field of reconstructive microsurgery became popular. Harry Buncke, MD, widely considered the founder of reconstructive microsurgery in the United States, trained generations of reconstructive microsurgeons after experimenting with various techniques in his garage (Figure 1). In this makeshift San Francisco laboratory, he bonded microscopic needles with fine sutures to enable him to anastomose blood vessels smaller than $1 \mathrm{~mm}$ in diameter (Figure 2). He and his wife, Constance Buncke, successfully reattached the ear of a rabbit in 1964 (Figure 3). He also successfully performed the first animal model toe-to-thumb transplant on a Rhesus Monkey. In the 1970s, Dr. Buncke subsequently performed the first toe-tothumb transplant in the United States on a firefighter who severed his thumb in a power saw accident (20) (Figure 4). He recruited his son, Gregory Buncke, as an operating 


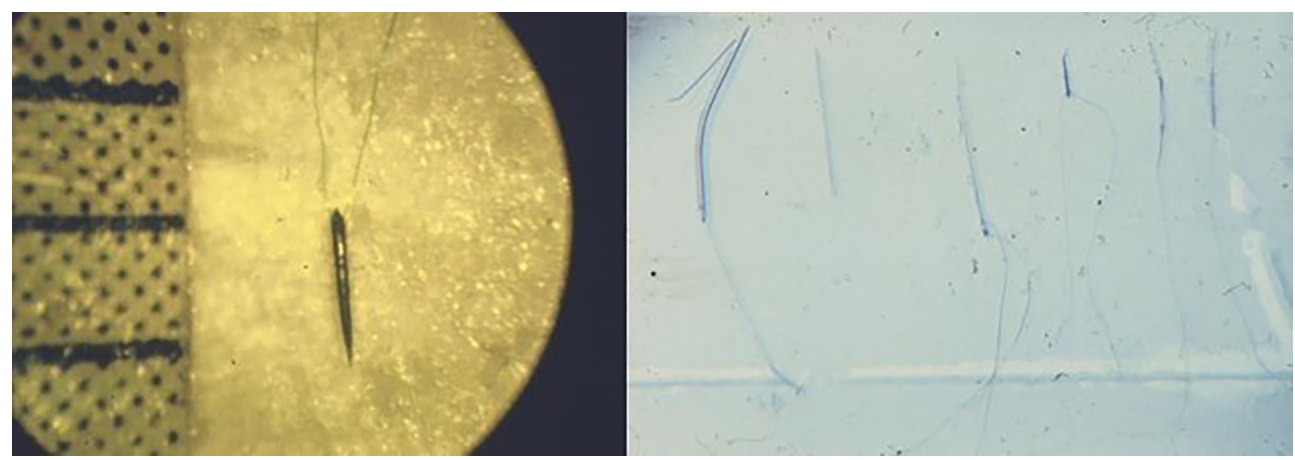

Figure 2 Photo of early microsutures developed in Dr. Buncke's garage laboratory. The hash marks in the left panel show millimeter marks on a ruler. The left panel also shows a single needle with fine silk suture looped through the needle "eye." The right panel shows the evolution of microsutures in which needles are molded to single-stranded microsutures (Photos courtesy of Dr. Gregory Buncke).

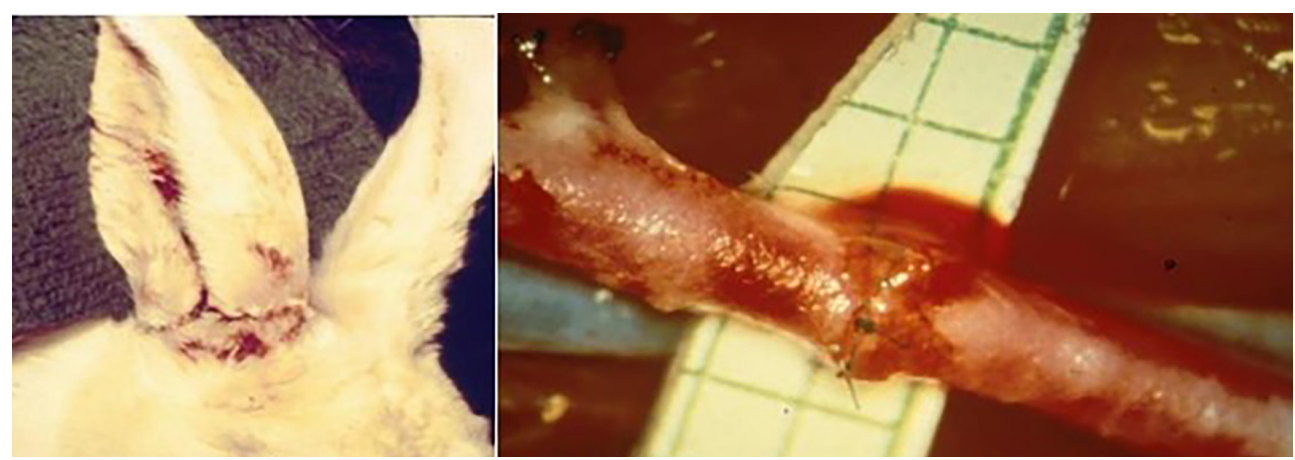

Figure 3 Amputation and reattachment of a rabbit ear. The right panel shows the first example of a successful $1 \mathrm{~mm}$ microvascular repair (Photos courtesy of Dr. Gregory Buncke).
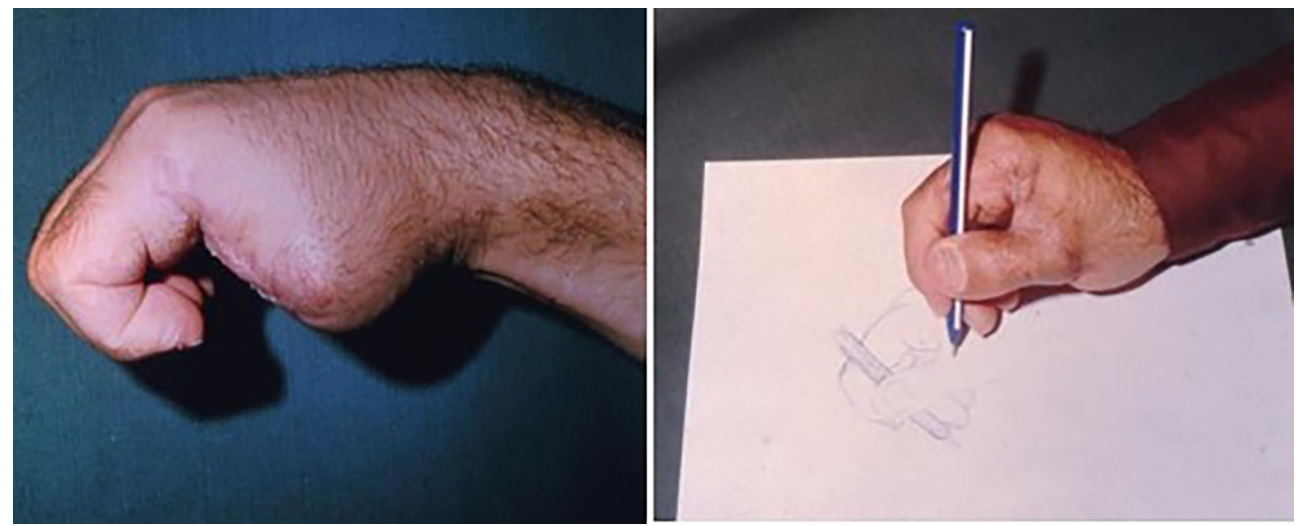

Figure 4 Before and after photos of a patient who underwent a toe-to-thumb transplantation (Photos courtesy of Dr. Gregory Buncke).

room photographer to document his work and promote the training of future generations of microsurgeons. Both Bunckes continued the mission of educating microsurgeons
(Figure 5), and with Harry Buncke's passing in 2008, his son and Drs. Rudy Buntic, Walter Lin, Bauback Safa, and Andrew Watt carry on The Buncke Clinic tradition of 


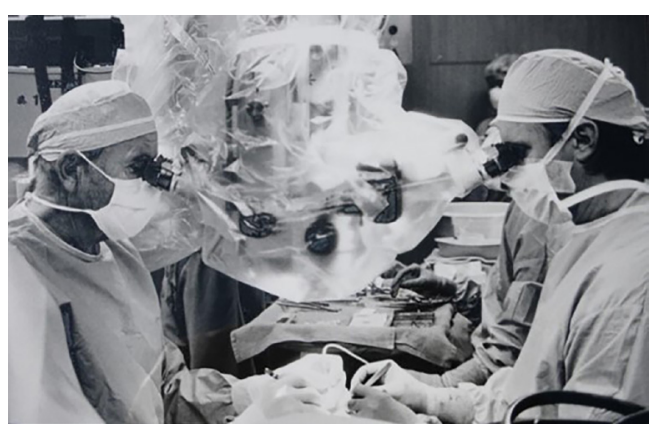

Figure 5 Harry Buncke, MD and son Gregory Buncke, MD operating under the microscope (Photo courtesy of Dr. Gregory Buncke).

teaching and performing ultrafine hand and reconstructive microsurgery.

\section{Microsurgery in urology}

\section{Renal revascularization}

The first kidney transplant was performed by Dr. Joseph Murray at Harvard's Brigham and Women's Hospital in 1954 without the use of an operating room microscope. This later earned Dr. Murray one of the only Nobel prizes in urology. The most common urologic revascularization procedure is kidney transplantation where the renal artery diameter is about $5 \mathrm{~mm}$ (21). Typically, renovascular surgery does not require microsurgery for success. However, in select cases, including renal autotransplantation and renal aneurysms from segmental arterial mediolysis, microscopic anastomotic techniques are helpful (22).

\section{Penile revascularization/transplantation/phalloplasty}

There is a burgeoning need for urologic microsurgery in cases of penile surgery. The main blood supply to the penis are the dorsal and deep penile arteries-branches from the common penile artery that originate from the internal pudendal artery. These vessels are $1-2 \mathrm{~mm}$ in diameter (23) and benefit greatly from microsurgical techniques. Penile arterial revascularization in cases of arteriogenic impotence due to blunt trauma or segmental injury are routinely performed microsurgically $(24,25)$. Revascularization of the penile arteries can be performed with patency rates greater than $50 \%(25,26)$ and was first reported by Dr. Vaclav Michal in 1973. Vascular bypass was performed between the inferior epigastric artery and corpus cavernosum (Michal
I) or the dorsal penile artery (Michal II) (25). The goal is to provide an alternative arterial supply to the penis with distal internal pudendal artery occlusion. Dr. Irwin Goldstein, trained by Dr. Michal in penile revascularization, has performed over 1,500 cases with excellent success rates. Recently, oral and injectable pharmacotherapy and the use of penile implants are more common choices for arteriogenic impotence given their wide accessibility, reliability, and relative ease of placement.

More recently, the field of gender surgery has taken advantage of microsurgical techniques to increase the success rates of phalloplasty procedures. The first reported female to male phalloplasty was reported in 1959-1960 in the Netherlands by Dr. Woudstra without the use of a free flap (27). The first free flap phalloplasty employing microsurgery was reported in 1982, and the first radial forearm free flap (RFFF) with a tube-in-tube design was published in $1984(28,29)$. The current gold standard and most commonly performed phalloplasty for transmen is the RFFF phalloplasty with full length urethroplasty (tubein-tube). The radial forearm donor site has a reliable and robust neurovascular network for a free flap and has the ideal tissue characteristics for creating a functional phallus (Figure 6). These characteristics include supple skin, easily identifiable arterial, venous, and nerve branches, and pliable adipose tissue. The average diameter of the radial artery is $2-3 \mathrm{~mm}$ and its collateral veins, including the cephalic vein, range from $1-2 \mathrm{~mm}$ in diameter-allowing for relatively simple microsurgical anastomoses $(30,31)$.

In brief, RFFF phalloplasty involves two microsurgeons and a reconstructive urologist (32) (Figure 7). The urologist performs the vaginectomy and pars fixa $(\mathrm{PF})$ urethroplasty using labia minora tissue to extend the urethra from the native urethral meatus to the tip of the glans clitoris. Dorsal nerve dissection is then performed after deepithelializing the clitoris and translocating it to the infrapubic position. A scrotum is created with labia majora flap elevation and rotational advancement, creating a pouchlike scrotum that is anteriorly positioned, followed by perineal reconstruction. The microsurgeons harvest the RFFF and create a neophallus and pars pendulans (PP) urethra. The neophallus is then brought to the pelvic midline where the PF and PP urethral anastomosis is completed. This is followed by dorsal nerve to antebrachial cutaneous nerve coaptation. Microsurgical anastomoses of the radial artery to the femoral artery and the venae comitantes and cephalic vein to branches of the saphenous vein are then carried out. Split thickness skin grafts are taken from the thigh to cover 

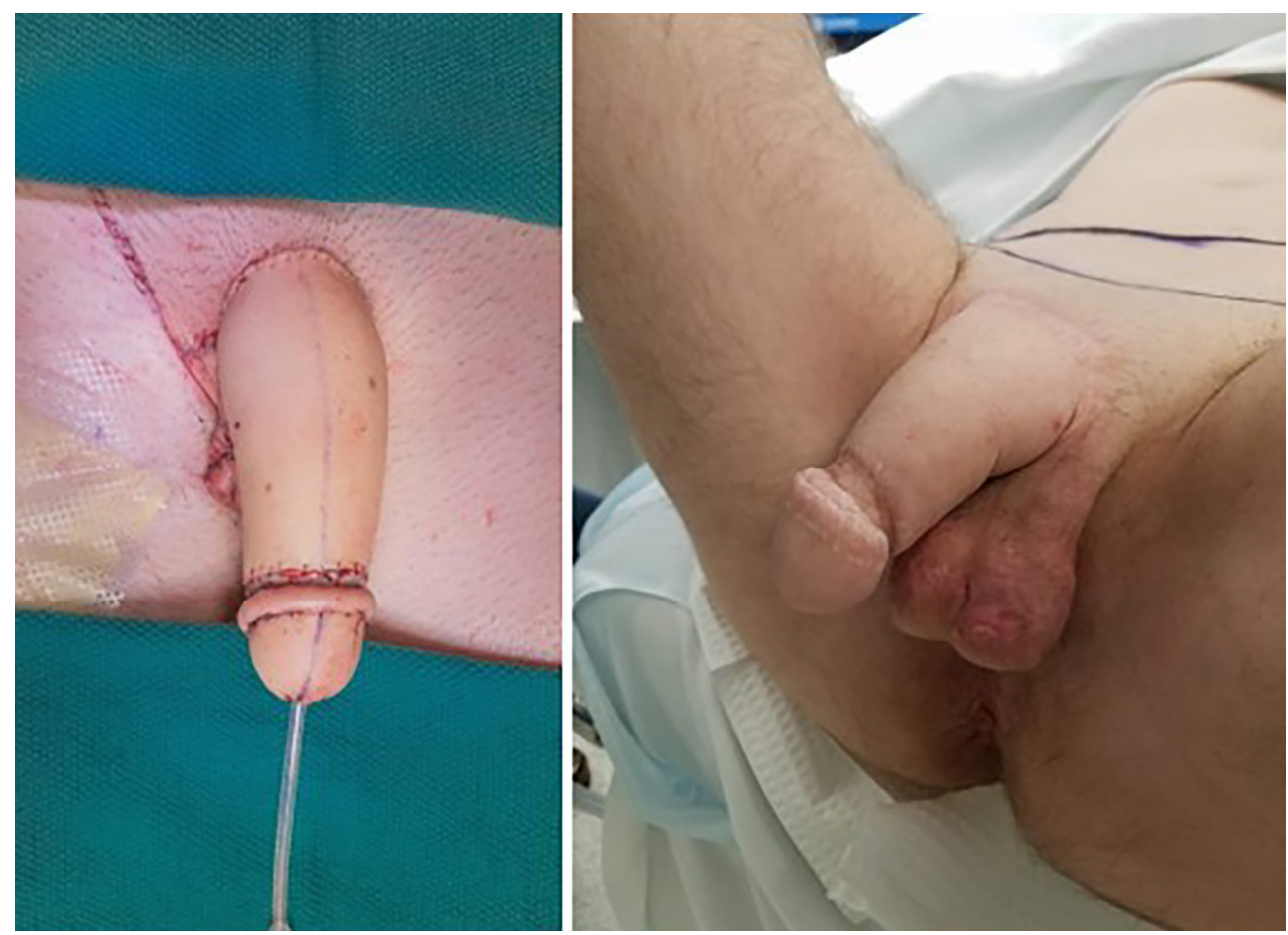

Figure 6 Radial forearm free flap phalloplasty: immediate postoperative photo (A) and 1-year postoperative photo (B).

the arm and the wounds are closed. Internal dopplers are placed on the dominant venous anastomosis and a marking stitch is placed on the neophallus where an external doppler can easily detect radial artery activity. Postoperatively, patients are monitored hourly with both the internal and external doppler for the first 24 hours, followed by every 2 -hour evaluation for another 24 hours. Thereafter, doppler evaluation is performed every $4-6$ hours until the patient is taken off bedrest and discharged from the hospital on the $5^{\text {th }}$ postoperative day.

Alternative phalloplasty flap options include the anterolateral thigh (ALT) pedicled/free flap, musculocutaneous latissimus dorsi (MLD) free flap, abdomen and groin local flaps, and lower extremity free flaps $(33,34)$. However, these donor sites have performance characteristics that are inferior to the RFFF, including less sensation, and higher urethral/aesthetic complication rates (35).

Even in experienced hands and high-volume centers, the overall complication rate in phalloplasty procedures is significant (36). In a metanalysis of RFFF phalloplasty (665 patients), the average reported complications per patient was 0.88 and the average strictures/fistulas per patient was $0.51(35)$. Urethral complication rates range from $25 \%$ to $58 \%$, which are likely underestimations given that only patients having urethral revision surgeries are included $(36,37)$. The most common site of urethral fistulas and strictures is the PF-PP urethral anastomosis. In general, patients with RFFF phalloplasty have fewer urethral strictures and fistulas than those with ALT phalloplasty $(38,39)$. Neophallus flap specific complications are fortunately low, with partial $(<8 \%)$ and complete $(<2 \%)$ flap loss rates decreasing as surgeon experience widens (40).

Over the last several years, the field of penile transplantation was born but only made possible with microsurgical advances. To date, there have been 3 cases reported (41). The first penile transplantation was performed in 2006 in China on a 44-year-old man who traumatically lost the pendulous portion of his penis (42). The technique involved microsurgical anastomosis of the dorsal nerves, the dorsal arteries and veins, with macroscopic anastomoses of the corpora cavernosa and corpora spongiosum and urethroplasty. The cold ischemia time was 15 hours with excellent immediate flap perfusion. The recipient was anticoagulated and immunosuppressed. The urethral catheter was removed 10 days later, and the patient voided. However, after two weeks, the patient requested removal of the penile allograft due to mental distress. 

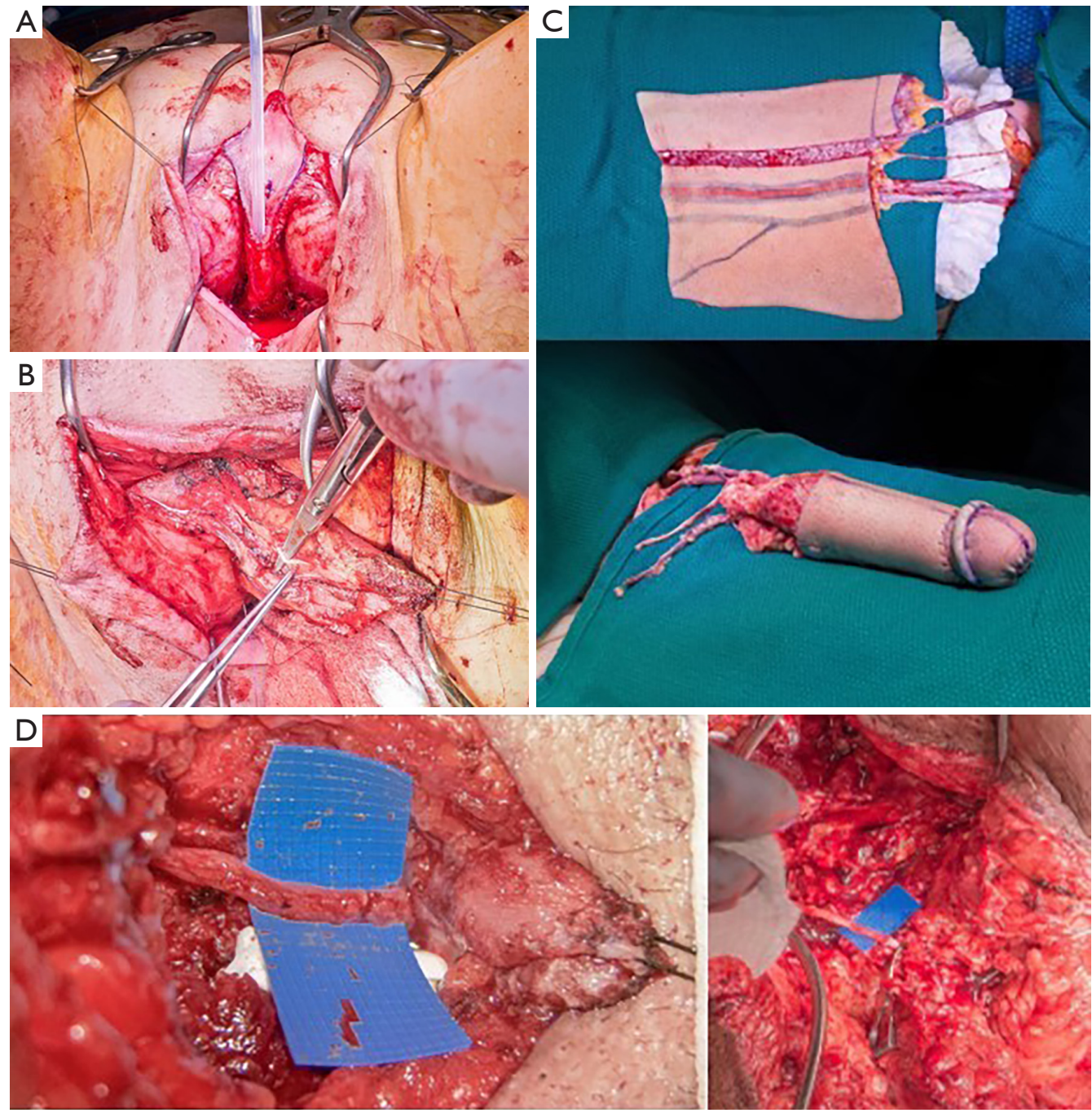

Figure 7 Creation of a neophallus using radial forearm free flap. (A) Vaginectomy and pars fixa (PF) urethroplasty using labia minora tissue to extend the urethra from the native urethral meatus to the tip of the clitoris. (B) Dorsal nerve dissection for later coaptation with the antebrachial cutaneous nerve(s) of the radial forearm free flap. (C) Radial forearm free flap based on brachial artery, prior to pars pendulans urethroplasty and neophallus creation. Neophallus created but not yet detached from brachial artery. (D) Microsurgical nerve coaptation using 9-0 suture between the dorsal nerve of the clitoris and the antebrachial cutaneous nerve (left panel) and microvascular anastomosis of cephalic vein to greater saphenous vein (right panel).

The second penile transplant was performed in South Africa on December 2014, where a 21-year-old recipient lost the pendulous portion of his penis from ritual circumcision. He required several procedures after the transplantation: clot removal from the artery; hematoma evacuation and urethral fistula repair. He was able to have spontaneous erections and impregnate his girlfriend within several months. The third penile transplant was performed in the United States at Harvard on a 64-year-old man who had had penectomy due to penile cancer (43). He developed hematomas requiring operative drainage as well as aggressive immunosuppression. By 7 months, the patient recovered penile shaft sensation and had spontaneous erections.

The microsurgical challenges in penile transplantation are numerous but center around three arteries (the external pudendal, cavernosal, and dorsal arteries), the venous drainage, and nerve anatomy. Donor penile skin viability 
relies on intact external pudendal arterial anastomoses. Cavernosal and dorsal artery anastomoses allow for spontaneous erections and are important for pendulous urethral perfusion. Optimal venous drainage is critical for reduced tissue edema. Nerve coaptation affords the return of erotic and tactile sensation in the grafted penis. From this limited world-wide experience, it appears critical that the donor penis have intact neurovasculature and viable soft tissue architecture for success.

\section{Testicular autotransplantation}

About $5 \%$ of undescended testes are considered high or intraabdominal. Therefore, local mobilization techniques like the Fowler-Stephens procedure are sometimes insufficient to allow for a fully intrascrotal postoperative result. In 1976, Dr. Cussen and his colleagues performed microsurgical anastomosis of canine testicular vessels as an experimental animal method for orchidopexy in a child with intraabdominal testes (44). Drs. Silber and Kelly described the first successful intraabdominal testis microvascular anastomosis in a child with prune belly syndrome around the same time (45). Since first performed in 1978, there has been another successful case described (46). The technical expertise required to perform this microsurgery has led most surgeons to continue to use alternatives such as orchiectomy $(47,48)$. For testis autotransplantation, the intraabdominal testis is dissected as a free graft and brought into the scrotum, followed by inferior epigastric vessel dissection and passage of the superiorly tracking vessels into the inguinal canal and scrotum inferiorly. The testicular artery and veins are anastomosed to branches of the inferior epigastric artery. The case is challenging as the testicular arteries have diameters between 0.5 and $1.0 \mathrm{~mm}$, and the inferior epigastric arteries are typically 1.0 to $1.5 \mathrm{~mm}$ wide; corresponding veins are typically $1.0 \mathrm{~mm}$ in diameter (48). End-to-end and sometimes endto-side vascular anastomoses are performed for testicular autotransplantation.

\section{Reproductive urology}

\section{Reproductive tract obstruction}

The field of urologic microsurgery was born with vasal and epididymal surgery. The most common reason for epididymal obstruction is vasectomy, a procedure which is 100 years old, and by consequence of change of heart by its recipients, has led to the development of vasectomy reversal surgery. Currently, among the 500,000 vasectomies performed in the US annually, $5 \%$ of men will seek reversal. And, depending on the length of time after the vasectomy is performed, many vasectomy patients will have secondary epididymal obstruction. Other causes of epididymal obstruction include trauma, epididymitis, Young syndrome, congenital anomalies, ejaculatory duct obstruction, and injury from hernia repair.

The history of epididymovasostomy surgery is long and storied. Before the era of the operating microscope (preWWII), early urologists attempted to connect the vas deferens to the epididymis with procedures that promoted fistula formation between the vas and epididymis rather than attempting a formal and direct anastomosis. In 1978, Silber first reported the microscopic approximation of the vasal mucosa directly to a single epididymal tubule in an endto-end manner (49). The next advance was the vasal end to epididymal tubule side anastomosis that was described by Fogdestam et al. in 1986 and popularized by Thomas in $1987(50,51)$. Given that the vasal lumen is approximately $250 \mu \mathrm{m}$ in diameter and an epididymal tubule is of similar size, these procedures remain technically very challenging to this day, even with the assistance of operative microscopy.

The most recent innovation in the epididymal-vasal anastomosis was described in $1991(52,53)$ and later popularized by Berger (54) and Marmar (55). It is termed "invagination" or "intussusception" epididymovasostomy. The essential difference between this technique and older end-to-side epididymovasostomy is found in the inner layer of the two-layer anastomosis. Instead of performing a formal mucosa-to-mucosa anastomosis of vas deferens to epididymis, a loop of epididymal tubule is intussuscepted or invaginated into the vasal lumen.

Briefly, a bloated epididymal tubule is prepared by careful isolation of a single epididymal tubule under high power microscopy. Instead of first opening the epididymal tubule for a mucosa-to-mucosa anastomosis, the invagination method involves suture placement through an intact, unopened tubule (Figure 8). The loop of isolated epididymal tubule is controlled with either 2 double armed 10.0 "vest" sutures placed in parallel or 3 sutures placed in the shape of a triangle. The needles are left within the tubule to guide the tubolotomy that follows. The suture arrangement creates a "double barrel" lumen from the loop of epididymal tubule which is later "invaginated" into the vas deferens lumen. The preplaced epididymal "vest" sutures are then placed in their corresponding positions deep within the vasal lumen in an inside-out direction (Figure 8). When 

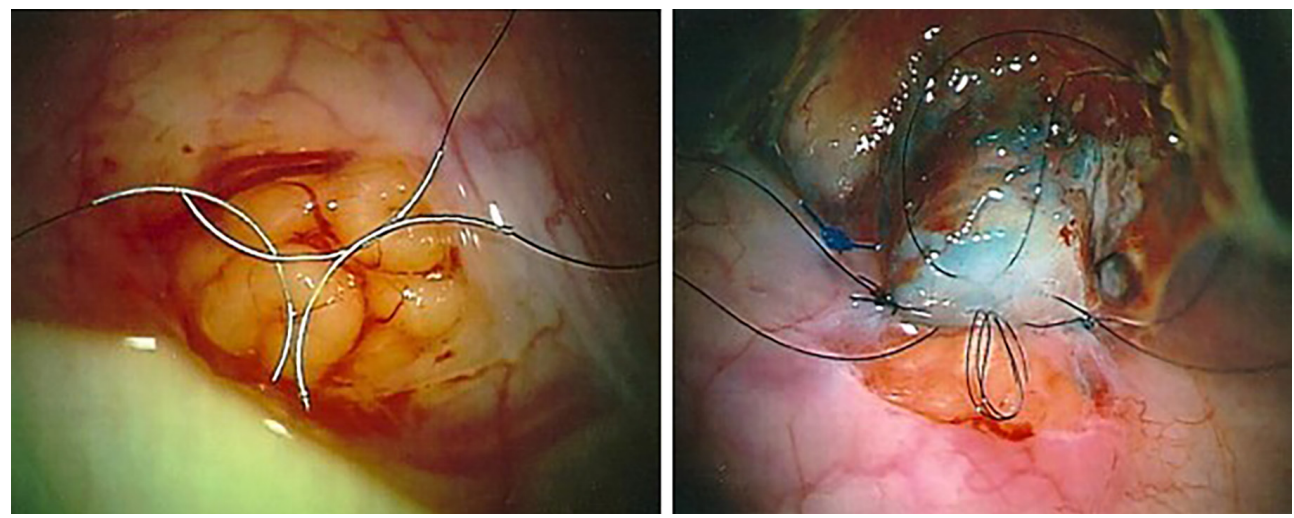

Figure 8 Microphotographs of the Berger triangulation invagination epididymovasostomy technique for vasectomy reversal (30x magnification). Left panel: Three 10.0 microsutures placed in a single epididymal tube as "vest" sutures. The epididymal tubule is then punctured and the microneedles advanced and placed inside-out into the vas deferens (right panel). Once the sutures are tied, the epididymal tubule is "invaginated" or advanced into the vas deferens lumen.

Table 1 Varicocele treatments: comparison of outcomes

\begin{tabular}{lccc}
\hline Outcome parameter & Microsurgical & Laparoscopic & Radiologic \\
\hline Semen improvement & $66 \%$ & $50-70 \%$ & $60 \%$ \\
Pregnancy rate & $35-50 \%$ & $12-32 \%$ & $10-50 \%$ \\
Technical failure rate & $<1 \%$ & $<1 \%$ & $10-15 \%$ \\
Recurrence rate & $0-5 \%$ & $5-25 \%$ & $5-25 \%$ \\
\hline
\end{tabular}

these sutures are tied, the epididymal tubule "invaginates" into the vas deferens lumen. This approach not only uses fewer sutures but also promises a better anastomotic seal than the mucosa-to-mucosa approach and is now widely used.

\section{Varicocelectomy}

Treatment of clinical varicoceles have also greatly benefited from the incorporation of microsurgery. The recognition that varicocele may be a factor in male infertility dates back to the first-century AD. The Greek physician Celsus noted in De Medicina: "The veins are swollen and twisted over the testicle, which becomes smaller than its fellow, in as much as nutrition has become defective" (56). The first demonstration of semen improvement and pregnancy after varicocele repair was reported by Barwell in 1885 and then by Bennett in 1889 (57,58). Over the last century, many surgical and radiological approaches have been used to treat clinical varicoceles, and with variable success rates as shown in Table 1. Historically, the surgical approaches have been either retroperitoneal (laparoscopy, incisional or radiographic embolization) or inguinal (incisional). In 1992, Goldstein et al. first reported a large series of inguinal hernia repairs using the operating microscope (59). Given the increased visualization and identification of the 1-2 mm gonadal arteries that are typically adherent to the pampiniform veins (59), Marmar [1994] began to perform varicocelectomies at the subinguinal level where more numerous veins [5-10] can be easily distinguished microscopically from 1-3 gonadal arteries that they surround, and where oblique muscle-splitting incisions are avoided (Figure 9) (60). Currently, the subinguinal microscopic varicocelectomy is considered the "gold standard" approach that maximizes procedural success and minimizes complications and recovery time for varicocele ligation (61).

\section{Sperm retrieval}

Surgical sperm retrieval procedures were first performed after in vitro fertilization was invented and became 


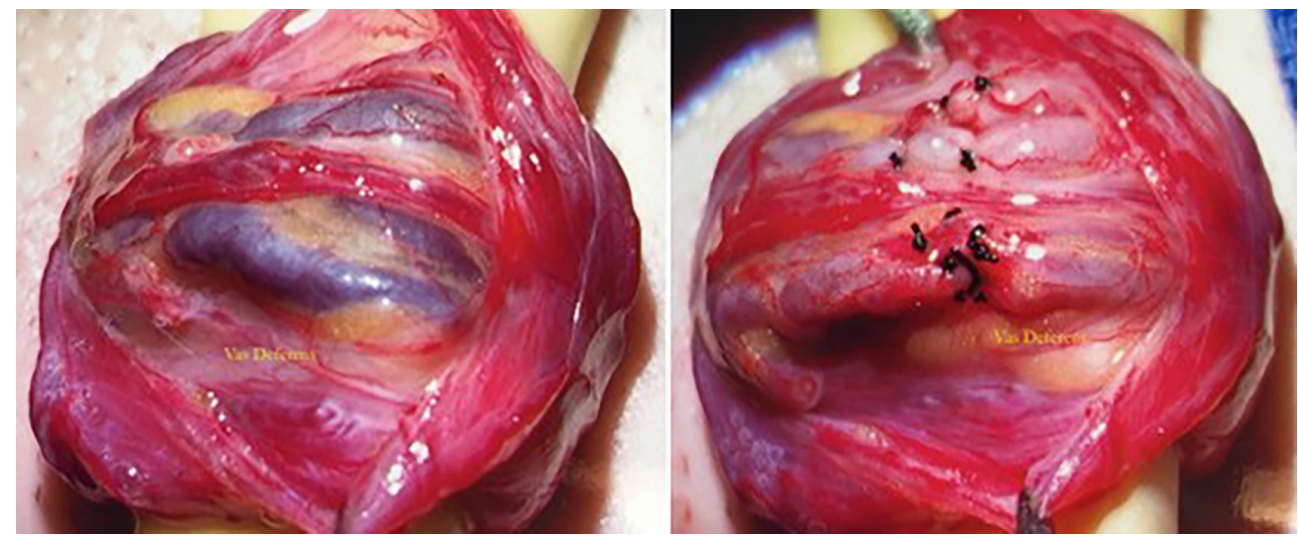

Figure 9 Subinguinal spermatic cord dissection and pampiniform vein ligation during varicocelectomy (10× magnification). Left panel: exposure of subinguinal spermatic cord with gonadal veins; Right panel: spermatic cord after ligation of gonadal veins. Vas deferens (labelled in yellow) and its veins and artery are excluded from the ligation.

enormously popular after intracytoplasmic sperm injection (ICSI) was developed in 1992. Sperm aspirated from the obstructed epididymis has been used with IVF since 1985 (62) and testicular sperm has been used with IVFICSI since 1993 (63). With epididymal sperm retrieval, operative microscopy now allows for the micromanipulation of individual epididymal tubules and improves the yield of motile sperm (64). Testicular sperm retrieval was originally performed by testicular biopsy which worked admirably in men with blockages but often failed in men with testicular failure (65). This is because in testis failure, sperm production occurs in "islands" or "patches" that can be missed with blindly performed procedures (66). The introduction of microdissection testicular sperm extraction employed operative microscopy to better identify individual testicular tubules that are more likely to contain sperm within the testis parenchyma (67) and quickly almost doubled the success rate of surgical sperm retrieval in cases of nonobstructive azoospermia (68).

\section{Conclusions}

The use of operative microscopy has vastly improved the technical ability of surgeons in urology and other disciplines to measurably increase patency rates, and to improve anastomotic precision and tissue viability. It also demonstrates that human manual dexterity is limited mainly by our vision and not by our coordination and dexterity. By increasing visual resolution, we take full advantage of our natural skillsets to accomplish what is improbable under direct vision.

\section{Acknowledgments}

Bauback Safa, MD, contributed to the manuscript but did not qualify for inclusion as an author.

Funding: None.

\section{Footnote}

Reporting Checklist: The authors have completed the Narrative Review reporting checklist. Available at http:// dx.doi.org/10.21037/tau-20-1441

Peer Review File: Available at http://dx.doi.org/10.21037/ tau-20-1441

Conflicts of Interest: All authors have completed the ICMJE uniform disclosure form (available at http://dx.doi. org/10.21037/tau-20-1441). The authors have no conflicts of interest to declare.

Ethical Statement: The authors are accountable for all aspects of the work in ensuring that questions related to the accuracy or integrity of any part of the work are appropriately investigated and resolved.

Open Access Statement: This is an Open Access article distributed in accordance with the Creative Commons Attribution-NonCommercial-NoDerivs 4.0 International License (CC BY-NC-ND 4.0), which permits the noncommercial replication and distribution of the article with the strict proviso that no changes or edits are made and the 
original work is properly cited (including links to both the formal publication through the relevant DOI and the license). See: https://creativecommons.org/licenses/by-nc-nd/4.0/.

\section{References}

1. Nylen COS. Något om de senaste 25 årens utveckling inom klinisk vestibularforskning, särskilt rörande labyrintfistelsymtom och lägenystagmus. Uppsala, Leipzig, A.-b: Lundequistska bokhandeln; 1942.

2. Dohlman GF. Carl Olof Nylen and the birth of the otomicroscope and microsurgery. Arch Otolaryngol 1969;90:813-7.

3. Schultheiss D, Denil J. History of the microscope and development of microsurgery: a revolution for reproductive tract surgery. Andrologia 2002;34:234-41.

4. Berland T, Perritt RA. Living with your eye operation. New York: St. Martin's Press, 1974.

5. Swolin K. Contribution to the surgical treatment of female sterility. Experimental and clinical studies. Acta Obstet Gynecol Scand 1967;46 Suppl:14-20.

6. Garcia CR. Current therapy of infertility, 1982-1983. B.C. Decker: Mosby, 1982.

7. Pastuszak AW, Wenker EP, Lipshultz LI. The history of microsurgery in urology. Urology 2015;85:971-5.

8. Owen ER. Microsurgical vasovasostomy: A reliable vasectomy reversal. Aust N Z J Surg 1977;47:305-9.

9. Silber SJ. Microscopic vasectomy reversal. Fertil Steril 1977;28:1191-202.

10. Bukowski TP, Wacksman J, Billmire DA, et al. Testicular autotransplantation for the intra-abdominal testis. Microsurgery 1995;16:290-5.

11. Chan P, Parekattil SJ, Goldstein M, et al. Pros and cons of robotic microsurgery as an appropriate approach to male reproductive surgery for vasectomy reversal and varicocele repair. Fertil Steril 2018;110:816-23.

12. Buncke HJ, Serafin D. Microsurgical composite tissue transplantation. Saint Louis: Mosby, 1979.

13. Buncke HJ. Microsurgery : transplantation—replantation. An atlas-text. Philadelphia: Lea \& Febiger, 1991.

14. Daniel RK, Terzis JK. Reconstructive microsurgery. 1st ed. Boston: Little, Brown, 1977.

15. Harii K. Microvascular tissue transfer: fundamental techniques and clinical applications. 1st ed. Tokyo; New York: Igaku-Shoin, 1983.

16. Tamai S, Usui M, Yoshizu T. Experimental and clinical reconstructive microsurgery. Tokyo; Hong Kong: Springer, 2003.
17. Tamai S. History of microsurgery. Plast Reconstr Surg 2009;124:e282-94.

18. Zumbé J, Beintker M, Denil J, et al. MESA and TESE: experiences of the German section of urological microsurgery. Andrologia 1996;28:89-92.

19. Millican KW. Human hair used for sutures long ago. JAMA 1910;8:631.

20. Rosson GD, Buncke GM, Buncke HJ. Great toe transplant versus thumb replant for isolated thumb amputation: critical analysis of functional outcome. Microsurgery 2008;28:598-605.

21. Turba UC, Uflacker R, Bozlar U, et al. Normal renal arterial anatomy assessed by multidetector CT angiography: are there differences between men and women? Clin Anat 2009;22:236-42.

22. Yoshioka T, Araki M, Ariyoshi Y, et al. Successful microscopic renal autotransplantation for left renal aneurysm associated with segmental arterial mediolysis. J Vasc Surg 2017;66:261-4.

23. Lue TF, Mueller SC, Jow YR, et al. Functional evaluation of penile arteries with duplex ultrasound in vasodilatorinduced erection. Urol Clin North Am 1989;16:799-807.

24. Hwang TI, Liu PZ, Yang CR. Evaluation of penile dorsal arteries and deep arteries in arteriogenic impotence. J Urol 1991;146:46-9.

25. Dicks B, Bastuba M, Goldstein I. Penile revascularization-contemporary update. Asian J Androl 2013;15:5-9.

26. Janssen T, Sarramon JP, Rischmann P, et al. Microsurgical arterio-arterial and arterio-venous penile revascularization in patients with pure arteriogenic impotence. $\mathrm{Br} \mathrm{J}$ Urol 1994;73:561-5.

27. Haeseker B, Nicolai JP. The first gender-changing operation from female to male in The Netherlands, 1959/'60. Ned Tijdschr Geneeskd 2007;151:548-52.

28. Song R, Gao Y, Song Y, et al. The forearm flap. Clin Plast Surg 1982;9:21-6.

29. Chang TS, Hwang WY. Forearm flap in one-stage reconstruction of the penis. Plast Reconstr Surg 1984;74:251-8.

30. Chong AY, Lo T, George S, et al. The effect of preprocedure sublingual nitroglycerin on radial artery diameter and Allen's test outcome - Relevance to transradial catheterization. Cardiovasc Revasc Med 2018;19:163-7.

31. Kordzadeh A, Chung J, Panayiotopoulos YP. Cephalic vein and radial artery diameter in formation of radiocephalic arteriovenous fistula: a systematic review. J Vasc Access 2015;16:506-11. 
32. Doornaert M, Hoebeke P, Ceulemans P, et al. Penile reconstruction with the radial forearm flap: an update. Handchir Mikrochir Plast Chir 2011;43:208-14.

33. Schechter LS, Safa B. Introduction to Phalloplasty. Clin Plast Surg 2018;45:387-9.

34. Xu KY, Watt AJ. The Pedicled Anterolateral Thigh Phalloplasty. Clin Plast Surg 2018;45:399-406.

35. Frey JD, Poudrier G, Chiodo MV, et al. A Systematic Review of Metoidioplasty and Radial Forearm Flap Phalloplasty in Female-to-male Transgender Genital Reconstruction: Is the "Ideal" Neophallus an Achievable Goal? Plast Reconstr Surg Glob Open 2016;4:e1131.

36. Monstrey S, Hoebeke P, Selvaggi G, et al. Penile reconstruction: is the radial forearm flap really the standard technique? Plast Reconstr Surg 2009;124:510-8.

37. Lumen N, Monstrey S, Goessaert AS, et al. Urethroplasty for strictures after phallic reconstruction: a singleinstitution experience. Eur Urol 2011;60:150-8.

38. Ascha M, Massie JP, Morrison SD, et al. Outcomes of Single Stage Phalloplasty by Pedicled Anterolateral Thigh Flap versus Radial Forearm Free Flap in Gender Confirming Surgery. J Urol 2018;199:206-14.

39. Massie JP, Morrison SD, Wilson SC, et al. Phalloplasty with Urethral Lengthening: Addition of a Vascularized Bulbospongiosus Flap from Vaginectomy Reduces Postoperative Urethral Complications. Plast Reconstr Surg 2017;140:551e-8e.

40. Esmonde N, Bluebond-Langner R, Berli JU. Phalloplasty Flap-Related Complication. Clin Plast Surg 2018;45:415-24.

41. Sopko NA, Tuffaha SH, Lough D, et al. Penile Allotransplantation for Complex Genitourinary Reconstruction. J Urol 2017;198:274-80.

42. $\mathrm{Hu} \mathrm{W}, \mathrm{Lu} \mathrm{J}$, Zhang L, et al. A preliminary report of penile transplantation. Eur Urol 2006;50:851-3.

43. Cetrulo CL Jr, Li K, Salinas HM, et al. Penis Transplantation: First US Experience. Ann Surg 2018;267:983-8.

44. MacMahon RA, O'Brien MC, Cussen LJ. The use of microsurgery in the treatment of the undescended testis. J Pediatr Surg 1976;11:521-6.

45. Silber SJ, Kelly J. Successful autotransplantation of an intra-abdominal testis to the scrotum by microvascular technique. J Urol 1976;115:452-4.

46. Grady D. Surgeons Transplant a Testicle from one Brother to His Twin. The New York Times. 2019. Available online: https://www.nytimes.com/2019/12/06/health/testiclestransplant.html
47. Hinman F Jr. Alternatives to orchiopexy. J Urol 1980;123:548-51.

48. Bukowski TP, Wacksman J, Billmire DA, et al. Testicular autotransplantation: a 17 -year review of an effective approach to the management of the intra-abdominal testis. J Urol 1995;154:558-61.

49. Silber SJ. Microscopic vasoepididymostomy: specific microanastomosis to the epididymal tubule. Fertil Steril 1978;30:565-71.

50. Fogdestam I, Fall M, Nilsson S. Microsurgical epididymovasostomy in the treatment of occlusive azoospermia. Fertil Steril 1986;46:925-9.

51. Thomas AJ Jr. Vasoepididymostomy. Urol Clin North Am 1987;14:527-38.

52. Shekarriz M, Pomer S. Microsurgical vasoepididymostomy: a comparison between the end-to-side anastomosis and the invagination technique. Urol Res 1991;19:285-7.

53. Stefanović KB, Clark SA, Buncke HJ. Microsurgical epididymovasostomy by loop intussusception. A new technique in the rat model. Br J Urol 1991;68:518-23.

54. Berger RE. Triangulation end-to-side vasoepididymostomy. J Urol 1998;159:1951-3.

55. Marmar JL. Modified vasoepididymostomy with simultaneous double needle placement, tubulotomy and tubular invagination. J Urol 2000;163:483-6.

56. Saypol D. Varicocele. J Androl 1981;2:61-71.

57. Barwell R. One hundred cases of varicocele treated by the subcutaneous wire loop. Lancet 1885;1:978.

58. Bennet $W$. Varicocele, particular with reference to its radical cure. Lancet 1889;1:261.

59. Goldstein M, Gilbert BR, Dicker AP et al. Microsurgical inguinal varicocelectomy with delivery of the testis: an artery and lymphatic sparing technique. J Urol 1992;148:1808-11.

60. Marmar JL, Kim Y. Subinguinal microsurgical varicocelectomy: a technical critique and statistical analysis of semen and pregnancy data. J Urol 1994;152:1127-32.

61. Cayan S, Shavakhabov S, Kadioglu A. Treatment of palpable varicocele in infertile men: a meta-analysis to define the best technique. J Androl 2009;30:33-40.

62. Temple-Smith PD, Southwick GJ, Yates CA, et al. Human pregnancy by in vitro fertilization (IVF) using sperm aspirated from the epididymis. J In Vitro Fert Embryo Transf 1985;2:119-22.

63. Craft I, Bennett V, Nicholson N. Fertilising ability of testicular spermatozoa. Lancet 1993;342:864.

64. Nudell DM, Lipshultz LI. Is intracytoplasmic sperm injection safe? Current status and future concerns. Curr 
Urol Rep 2001;2:423-31.

65. Shin DH, Turek PJ. Sperm retrieval techniques. Nat Rev Urol 2013;10:723-30.

66. Turek PJ, Ljung BM, Cha I, et al. Diagnostic findings from testis fine needle aspiration mapping in obstructed and nonobstructed azoospermic men. J Urol 2000;163:1709-16. 67. Schlegel PN. Testicular sperm extraction: microdissection improves sperm yield with minimal tissue excision. Hum Reprod 1999;14:131-5.

68. Bernie AM, Mata DA, Ramasamy R, et al. Comparison of microdissection testicular sperm extraction, conventional testicular sperm extraction, and testicular sperm aspiration for nonobstructive azoospermia: a systematic review and meta-analysis. Fertil Steril 2015;104:1099-103.e1.
Cite this article as: Chen ML, Buncke GM, Turek PJ. Narrative review of the history of microsurgery in urological practice. Transl Androl Urol 2021;10(4):1780-1791. doi: 10.21037/ tau-20-1441 